\title{
Relative bioavailability of 3 rumen-undegradable methionine sources in dairy cows using the area under the curve technique
}

\author{
A. Kihal, $\odot$ M. Rodriguez-Prado, $\odot$ and S. Calsamiglia* $\odot$
}

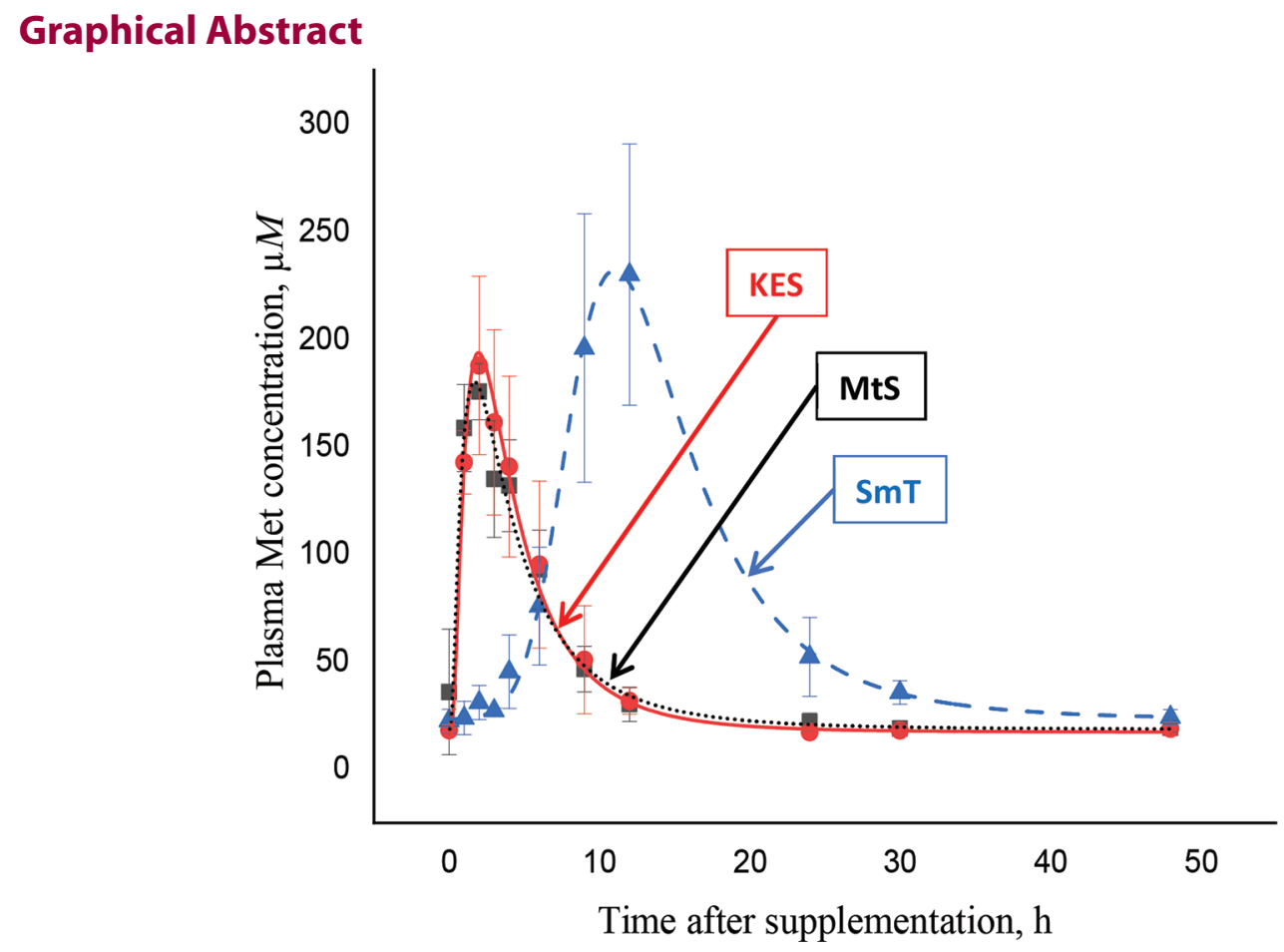

\section{Summary}

The relative bioavailability of 2 Met hydroxy analogs (KES and MtS) and a rumen-protected Met (SmT) was determined using the area under the curve method. Relative Met bioavailability was similar between the 3 methionine hydroxy analogs, but the area under the curve was greater for the rumen-protected Met.

\section{Highlights}

- Plasma kinetics of 3 sources of metabolizable Met were tested.

- The two 2-hydroxy-4-(methylthio)butanoic isopropyl ester products (Kessent, Kemin Animal Nutrition and Health, KES; Metasmart, Adisseo SAS, MtS) had a similar pattern.

- Smartamine (Adisseo SAS, SmT) peaked later and had a greater area under the curve.

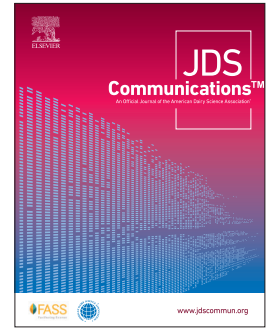




\title{
Relative bioavailability of 3 rumen-undegradable methionine sources in dairy cows using the area under the curve technique
}

\author{
A. Kihal, $\odot$ M. Rodriguez-Prado, $\odot$ and S. Calsamiglia* $\odot$
}

\begin{abstract}
The objective of this study was to evaluate the relative bioavailability of two 2-hydroxy-4-(methylthio)butanoic isopropyl esters (HMBi) obtained through different production processes and an encapsulated rumen-protected Met using the area under the curve (AUC) method. The new HMBi product (Kessent MF Liquid, Kemin Animal Nutrition and Health) was compared with an existing HMBi product (Metasmart, Adisseo SAS) and a pH-sensitive coated Met (Smartamine, Adisseo SAS). Nine multiparous lactating cows (30 kg of milk/d and $227 \mathrm{~d}$ in milk) fed a 45:55 forage:concentrate diet were randomly assigned within square to a triplicate $3 \times 3$ Latin square design. Each period consisted of a 3-d sampling period and a 3-d washout period. Treatments were dosed on $\mathrm{d} 1$ of each period, and blood samples were collected from the coccygeal vein at $0,1,2,3,4,6,9,12,24,30$, and $48 \mathrm{~h}$ thereafter. The daily dose was $50 \mathrm{~g}$ of Met equivalent of each treatment. The HMBi treatments were administered directly into the cow's mouth, whereas Smartamine was fed mixed with $0.5 \mathrm{~kg}$ of concentrate and fully consumed within $15 \mathrm{~min}$. Nonlinear models were fitted to raw data, and the basal concentration at time $0 \mathrm{~h}$, time at peak (Tmax), concentration at peak, and AUC of plasma Met were determined. The Met basal concentration at $\mathrm{t}=0 \mathrm{~h}$ $(26.7 \pm 7.67 \mu M)$ and concentration at peak $(210 \pm 22.2 \mu M)$ were similar among treatments, but the Tmax (11.3 vs. $1.4 \mathrm{~h})$ was delayed and the AUC was 1.8-fold larger (3,457 vs. 1,868 arbitrary units) in Smartamine compared with HMBi. Results of this study indicate that the 2 HMBi products have similar plasma kinetics and bioavailability. Smartamine had different kinetics compared with HMBi products, with delayed Tmax and larger AUC and relative bioavailability.
\end{abstract}

$T^{1}$ he AA profile of microbial protein is similar to that of casein and balanced in essential AA for milk production, particularly Lys and Met. In high-producing dairy cows, microbial protein provides 50 to $60 \%$ of the total AA requirements; the remainder is supplied by dietary RUP (Schwab and Broderick, 2017). Most dietary protein sources have an AA profile with lower Lys and Met compared with microbial protein. Therefore, the high-quality AA profile of microbial protein tends to be diluted as the contribution of dietary AA to the total supply of AA increases, making most diets for high-producing dairy cows deficient in Lys and Met. Industry has developed different methods to increase the supply of bioavailable AA to dairy cows (Schwab et al., 2001; Rulquin and Kowalczyk, 2003; Graulet et al., 2005). One of the limitations of many of these products is that they are sensitive to thermal and physical processing, often occurring during pelleting. An alternative method to supply bioavailable AA to dairy cows would be to use AA analogs that are able to avoid ruminal degradation and be transformed into the active form of the AA after absorption. 2-Hydroxy-4-(methylthio)butanoic acid (HMB) is a Met analog in which the amide group is replaced by a hydroxyl group and is converted into Met after absorption. The esterification of HMB with alcohol groups has been reported to enhance its bioavailability.

$\alpha$-Hydroxy ester analogs of natural AA can be produced via biological, biotransformation, or chemical synthetic processes (Michel et al., 2000, 2001; Chuanlong et al., 2015; Sadaba Zubiri et al., 2016). Synthesis of the isopropyl ester of hydroxy analog of methionine (HMBi) typically uses acid-catalyzed Fischer esterifi- cation of the corresponding acid and an alcohol in the presence of acid catalyst, hydrolysis of the corresponding nitrile in the presence of a strong acid, or enzyme-mediated processes. Current methods provide low yields and require complex downstream purification techniques. A new proprietary process to produce HMBi using mild reaction conditions and safer handing has been developed (Kemin Animal Nutrition and Health). This process results in a high-quality product of up to $99 \%$ purity.

Bioavailability of HMBi ranges from 40 to $58 \%$ (Robert et al., 2001; Schwab et al., 2001; Graulet et al., 2005). After absorption through the rumen epithelium, HMBi is hydrolyzed to HMB and isopropanol that are converted to Met and acetone in the liver, respectively (Graulet et al., 2005). Supplementation with $\mathrm{HMBi}$ has been reported to increase milk and protein yields in dairy cows (Rulquin et al., 2006; Ordway et al., 2009).

We hypothesized that the new HMBi would have a bioavailability similar to that of the existing HMBi products and would be different from other coated-protected Met. The objective of this study was to determine the bioavailability of $2 \mathrm{HMBi}$ produced by different processes and compare them with a $\mathrm{pH}$-sensitive coated Met using the area under the curve (AUC) method.

The study was approved by the Human and Animal Research Ethic Committee of the Universitat Autònoma de Barcelona (Barcelona, Spain; protocol no. 4652). Nine multiparous HolsteinFriesian cows in late lactation ( $30 \mathrm{~kg}$ of milk/d and $227 \mathrm{DIM}$ ) were housed in a freestall barn and fed ad libitum a TMR once daily at $1000 \mathrm{~h}$ and had free access to water. The diet was formulated 
to meet or exceed ME (100\%), protein $(110 \%)$, Lys $(110 \%)$, and Met $(100 \%)$ requirements of a $700-\mathrm{kg}$ Holstein cow producing 30 $\mathrm{kg}$ of milk using the Cornell Net Carbohydrate and Protein System (AMTS.Cattle, Agricultural Modeling and Training Systems LLC). The diet consisted of (DM basis) $28.8 \%$ corn silage, $24.4 \%$ soybean meal, $16.8 \%$ grass silage, $10.8 \%$ corn grain ground fine, $8.4 \%$ barley grain, $7.8 \%$ vitamin-mineral mix, $2.0 \%$ wheat straw, and $1.0 \%$ calcium carbonate. The diet contained (DM basis) $18.4 \%$ CP, $30.0 \% \mathrm{NDF}, 34.6 \% \mathrm{NFC}, 21.1 \%$ starch, and $3.0 \%$ ether extract

The experiment was designed as a triplicate $3 \times 3$ Latin square with 9 cows. Cows were randomly assigned to one of the squares and, within square, to treatments. Treatments were $2 \mathrm{HMBi}$ [Kessent, Kemin Animal Nutrition and Health (KES); Metasmart, Adisseo SAS (MtS)] and a pH-sensitive coated Met (Smartamine, Adisseo SAS; SmT). Each period consisted of $6 \mathrm{~d}$ ( 3 experimental days followed by $3 \mathrm{~d}$ of washout between periods). Treatments were dosed the first day at $50 \mathrm{~g}$ of Met equivalent of each treatment just before feeding. The KES and MtS were administered as a liquid solution directly into the cow's mouth with a $100-\mathrm{mL}$ syringe followed by $300 \mathrm{~mL}$ of water to ensure the complete ingestion of treatments. The SmT was fed mixed with approximately $0.5 \mathrm{~kg}$ of concentrate and was fully consumed within $15 \mathrm{~min}$. Blood samples were collected before supplying treatments $(0 \mathrm{~h})$ and at $1,2,3,4$, $6,9,12,24,30$, and $48 \mathrm{~h}$ after treatment supply. Samples were collected from the tail vascular pack into $10 \mathrm{~mL}$ of EDTA-coated Vacutainers tubes $\left(\mathrm{K}_{2} \mathrm{E}, \mathrm{BD}\right)$. After collection, samples were immediately centrifuged at $1,000 \times g$ for $10 \mathrm{~min}$ at room temperature to extract blood plasma. Samples were aliquoted into $2-\mathrm{mL}$ polypropylene cryovials and stored at $-80^{\circ} \mathrm{C}$ until AA analysis.

For the analysis of AA, $100 \mu \mathrm{L}$ of plasma samples was placed in Eppendorf tubes. Then, $200 \mu \mathrm{L}$ of an acetonitrile:methanol solution (50:50, with $0.1 \%$ of formic acid) was added to samples for protein precipitation. Samples were homogenized with a multivortex mixer for $5 \mathrm{~min}$ and then centrifuged at 23,000 $\times \mathrm{g}$ for $5 \mathrm{~min}$ at $4^{\circ} \mathrm{C}$. The organic phase was collected and placed in a polypropylene conical HPLC vial for injection in the chromatographic system. The analysis consisted of a hydrophilic interaction chromatography HPLC/MS technique at low $\mathrm{pH}$ as described by Kennedy and Bivens (2017). The HPLC (no. 1260, Agilent) was equipped with a double column (InfinityLab Poroshell 120 HILIC$\mathrm{Z}$ and $\mathrm{OH}$, Agilent) with 2 ammonium formate mobile phases at $\mathrm{pH} 3$, one diluted in water and the other in acetonitrile. Substrates were detected with an MS-triple quadrupole detector (G6420, Agilent) with the ionization source in positive mode.

A range of nonlinear models were fitted to raw data of plasma Met concentrations after treatment supplementation using OriginLab 2000 (OriginLab Corp.) and selected based on Akaike's information criterion and residual plot analysis. Basal plasma Met concentration at $0 \mathrm{~h}$ was considered the basal Met concentration for each cow and period and was used to calculate the AUC using the trapezoidal method. The maximal concentration (Cmax), time at Cmax (Tmax), and AUC were determined using the fitted curve values.

Data from Met kinetics were analyzed according to a triplicate 3 $\times 3$ Latin square design using PROC MIXED of SAS (version 9.4; SAS Institute Inc.). The linear mixed model used was

$$
\mathrm{Y}_{\mathrm{ijk} \mathrm{l}}=\mu+\mathrm{T}_{\mathrm{i}}+\mathrm{P}_{\mathrm{j}}+\mathrm{C}_{\mathrm{k}}+\mathrm{LS}_{1}+\varepsilon_{\mathrm{ijk} \mathrm{l}},
$$

where $Y_{\mathrm{ijk}}=$ variable responses (basal concentration, Cmax, Tmax, and AUC); $\mu=$ overall mean; $T_{i}=$ fixed effect of treatment $(i=$ KES, MtS, or SmT); $P_{j}=$ fixed effect of period; $C_{k}=$ random effect of cow; $\mathrm{LS}_{1}=$ fixed effect of the square; and $\varepsilon_{\mathrm{ijk}}=$ residual errors. The assumptions of normality and homogeneity of variance were checked graphically using histograms, normal quantile plots, and plots of residuals versus fitted predicted values. Results are reported as least squares means and associated standard errors. Statistical significance was declared at $P \leq 0.05$. When treatment was significant, comparisons between treatment means for all response variables were performed using the Tukey test.

The selected curve that fitted data was the Gauss model:

$$
\begin{aligned}
\mathrm{y}=\mathrm{y} 0+\mathrm{A} / \mathrm{t} 0 & \times \exp \left[0.5 \times(\mathrm{w} / \mathrm{t} 0)^{2}-(\mathrm{x}-\mathrm{xc}) / \mathrm{t} 0\right] \\
& \times\{\operatorname{erf}[\mathrm{z} / \operatorname{sqrt}(2)]+1\} / 2
\end{aligned}
$$

where $\mathrm{y} 0$ is the concentration at time $0, \mathrm{~A}$ is the area, to is the time at peak, $\mathrm{w}$ is the width of the curve; $\mathrm{x}$ is the concentration, and $\mathrm{xc}$ is the Cmax. For MsT, KES, and SmT, respectively, y0 was 19.6, 18.1 , and 23.3 ; A was 838,942 , and 2,117 ; t0 was $3.679,3.973$, and 5.181; w was $0.530,0.203$, and 2.413; and $\mathrm{xc}$ was $0.756,0.976$, and 8.608.and. Plasma kinetics of Met concentrations were not different between KES and MsT (Table 1; Figure 1). Average basal Met concentration of KES and MsT at $0 \mathrm{~h}$ was $28.3 \pm 7.67 \mu \mathrm{M}$. Blood Met peaked rapidly without lag time at $1.4 \pm 0.25 \mathrm{~h}$ after HMBi product supplementation and reached an average concentration of $198 \pm 22.2 \mu M$, which was 7-fold higher than the basal concentration. Plasma Met returned to basal values at $24 \mathrm{~h}$ (Figure 1). The AUC of the 2 treatments was similar and averaged $1,868 \pm$ 286 arbitrary units (AU; Table 1).

The AUC method is useful for measuring the relative bioavailability of metabolites. Smartamine is a well-studied rumenprotected Met product and was used herein as a positive control for comparison purposes (Graulet et al., 2005). Plasma Met concentration after SmT supplementation had a different pattern compared with KES and MsT, as expected. The basal $(26.7 \pm 7.67 \mu M)$ and Cmax $(210 \pm 22.2 \mu M)$ Met concentrations were similar to those in the HMBi treatments. The Met Tmax was longer in SmT compared with the HMBi treatments ( 11.3 vs. $1.4 \pm 0.25 \mathrm{~h}$, respectively). The AUC of SmT was 1.85-fold higher than that of the HMBi treatments (3,457 vs. $1,868 \pm 286 \mathrm{AU}$, respectively).

Basal plasma Met concentration was in the range of basal values of dairy cows (Pisulewski et al., 1996; Koenig et al., 2002). The Cmax, Tmax, and AUC values of the HMBi treatments were close to those reported by Graulet et al. $(2005 ; 145 \mu M, 2 \mathrm{~h}$, and 1,698 $\mathrm{AU}$, respectively), who conducted the experiment with dry Holstein cows. The early Tmax of Met concentration is the result of the rapid absorption of HMBi in the rumen wall by passive diffusion or by monocarboxylate transporter 1 localized in the rumen epithelium (Kirat et al., 2006). However, the postabsorption metabolism of HMBi is not clearly elucidated in the literature. Robert et al. (2002) and Breves et al. (2010) reported that HMBi is first hydrolyzed in rumen wall cells into HMB and then transported to the liver to be converted to Met. In contrast, Graulet et al. (2005) reported that HMB concentration peaked in peripheral blood (not in the portal vein) $1 \mathrm{~h}$ after HMBi supply, which suggests that HMB has been through the liver before its distribution in peripheral blood. Lob- 
Table 1. Methionine plasma kinetics characteristics of the 2-hydroxy 4-(methylthio)-butanoic acid isopropyl ester treatments ${ }^{1}$ and rumen-protected Met $^{2}$ supplemented to dairy cows

\begin{tabular}{lccccc}
\hline Index $^{3}$ & Kessent & Metasmart & Smartamine & SEM & $P$-value \\
\hline Cbasal, $\mu M$ & 22.3 & 34.3 & 23.4 & 7.67 & 0.50 \\
Cmax, $\mu M$ & 202 & 194 & 234 & 22.2 & 0.29 \\
Tmax, $\mathrm{h}$ & $1.6^{\mathrm{b}}$ & $1.2^{\mathrm{b}}$ & $11.3^{\mathrm{a}}$ & 0.25 & $<0.01$ \\
AUC, AU & $1,885^{\mathrm{b}}$ & $1,850^{\mathrm{b}}$ & $3,457^{\mathrm{a}}$ & 286 & $<0.01$ \\
\hline
\end{tabular}

${ }^{\mathrm{a}, \mathrm{b}}$ Different superscripts within a row indicate significant effects $(P<0.05)$.

${ }^{1}$ Kessent MF Liquid (Kemin Animal Nutrition and Health) and Metasmart (Adisseo SAS).

${ }^{2}$ Smartamine (Adisseo SAS).

${ }^{3}$ Cbasal: basal concentration at $\mathrm{t}=0 \mathrm{~h}$; Cmax: maximal concentration; Tmax: time at Cmax; AUC: area under the curve; AU: arbitrary units.

ley et al. (2006) and Lapierre et al. (2007) conducted studies on HMB (not HMBi) supply to dairy cows. A net appearance of $11 \%$ of HMB supplied in portal vein blood following 1 oral dose was observed. However, no significant increase of Met in arterial blood was detected. The authors reported that 65 to $75 \%$ of absorbed HMB flows beyond the liver to be converted to Met in peripheral tissues and retained for protein gain in the target organs. Therefore, if the hydrolysis of HMBi to HMB happens in the rumen wall, HMB would follow the same metabolic process reported for HMB by Lobley et al. (2006) and Lapierre et al. (2007) and no relevant concentrations of Met in blood would be detected, in contrast to the results herein and in Graulet et al. (2005). It could be that HMBi is only partially hydrolyzed to HMB in the liver before its release into peripheral blood and not in the rumen wall. Therefore, an analysis of HMBi content in the portal blood may be useful to clarify its metabolism. In summary, the HMB pathway throughout the body

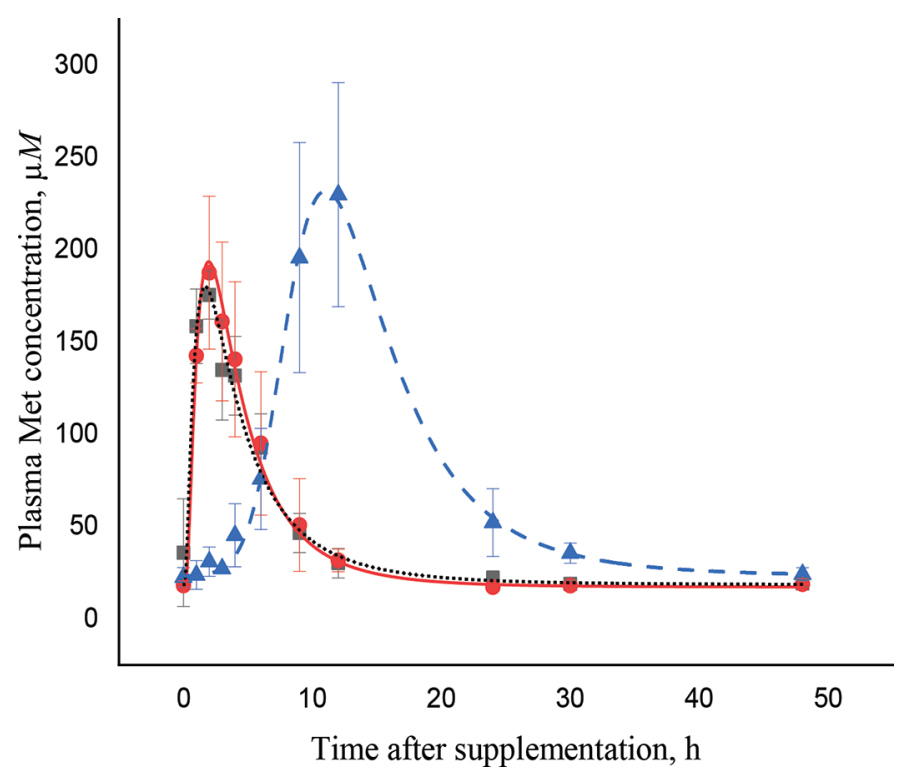

Figure 1. Evolution of methionine plasma kinetics $( \pm S E)$ as a function of time from administration of 2-hydroxy-4-(methylthio)butanoic isopropyl ester products (Kessent MF Liquid, Kemin Animal Nutrition and Health, $\bullet$;

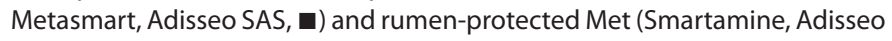
SAS, $\mathbf{4}$ ) to $48 \mathrm{~h}$. is not yet clear, and it is possible that HMB and HMBi metabolism differ.

The $\mathrm{pH}$-sensitive coating of SmT protects Met molecules from rumen degradation, but when $\mathrm{SmT}$ particles flow to the abomasum, the acidic conditions release Met that becomes available for absorption in the small intestine (Graulet et al., 2005). Small particles may flow with the liquid or solid fraction depending on particle size and density. The particle size and density of SmT (1.4-2.5 $\mathrm{mm}$ and $0.7 \mathrm{~g} / \mathrm{cm}^{3}$, respectively) may affect mean retention time (MRT) in the rumen. Dufreneix et al. (2019) suggested that small particles with a density of $<0.9 \mathrm{~g} / \mathrm{cm}^{3}$ would results in long MRT in the rumen $(39.6 \mathrm{~h})$ compared with particles with a density of 1.1 to $1.4 \mathrm{~g} / \mathrm{cm}^{3}$. Therefore, the slow flow of SmT through the rumen and abomasum may explain the Tmax delay in SmT.

Few studies have evaluated Met plasma concentration kinetics after SmT supplementation. Graulet et al. (2005) reported that Met plasma concentration peaked at $22 \mathrm{~h}$, later than the $11.3 \mathrm{~h}$ in our study. However, they used limited-fed nonpregnant dry cows with a 75:25 forage:concentrate diet, which may have increased MRT in the rumen and resulted in a particularly long delayed peak. The lower Cmax reported $(178 \pm 12.8 \mu M)$ may also be attributed to the longer MRT. However, the AUC ratio between HMBi and SmT was similar to the one reported in our study (1.87- vs. 1.85-fold, respectively). The fact that $\mathrm{HMBi}$ kinetic results were similar to those of other studies but not those of SmT may be attributed to the fact that HMBi is absorbed in the rumen and not affected by level of intake or type of diet, whereas the MRT of SmT may have been affected by the lower DMI and higher forage proportion in the diet in Graulet et al. (2005), where experimental cows were nonlactating and nonpregnant.

The determination of true bioavailability is complex and requires a complex and long experimental design (Whitehouse et al., 2017). The AUC method is a faster, less expensive, and effective alternative; however, it gives only a relative value of bioavailability. Results of this study indicate that the Tmax, Cmax, AUC, and, therefore, relative bioavailability of the newly developed $\mathrm{HMBi}$ (KES) are similar to those of MtS. Smartamine had different kinetics compared with HMBi, with delayed Tmax and larger AUC and relative bioavailability.

\section{References}

Breves, G., B. Schröder, W. Heimbeck, and R. A. Patton. 2010. Short communication: Transport of 2-hydroxy-4-methyl-thio-butanoic isopropyl ester by rumen epithelium in vitro. J. Dairy Sci. 93:260-264. https://doi.org/10 .3168/jds.2009-2200. 
Chuanlong, W., Q. Ling, Y. Fan, W. Yonggui, L. Ou, and C. Hongyang. 2015. Method for preparing high-purity 2-hydroxy-4-methylthio butyrate. Patent No. CN2014-10738814.

Dufreneix, F., P. Faverdin, and J. L. Peyraud. 2019. Influence of particle size and density on mean retention time in the rumen of dairy cows. J. Dairy Sci. 102:3010-3022. https://doi.org/10.3168/jds.2018-15926.

Graulet, B., C. Richard, and J. C. Robert. 2005. Methionine availability in plasma of dairy cows supplemented with methionine hydroxy analog isopropyl ester. J. Dairy Sci. 88:3640-3649. https://doi.org/10.3168/jds .S0022-0302(05)73049-6.

Kennedy, A., and A. Bivens. 2017. Methods for the analysis of underivatized amino acids by LC/MS. Application Note. 5991-8582EN. Agilent Technologies.

Kirat, D., J. Masuoka, H. Hayashi, H. Iwano, H. Yokota, H. Taniyama, and S. Kato. 2006. Monocarboxylate transporter 1 (MCT1) plays a direct role in short chain fatty acids absorption in caprine rumen. J. Physiol. 576:635647. https://doi.org/10.1113/jphysiol.2006.115931.

Koenig, K. M., L. M. Rode, C. D. Knight, and M. Vázquez-Añón. 2002. Rumen degradation and availability of various amounts of liquid methionine hydroxy analog in lactating dairy cows. J. Dairy Sci. 85:930-938. https:// doi.org/10.3168/jds.S0022-0302(02)74151-9.

Lapierre, H., M. Vázquez-Añón, D. Parker, P. Dubreuil, and G. E. Lobley. 2007. Short communication: Absorption of 2-hydroxy-4-methylthiobutanoate in dairy cows. J. Dairy Sci. 90:2937-2940. https://doi.org/10.3168/jds.2006 $-556$.

Lobley, G. E., T. G. Wester, A. G. Calder, D. S. Parker, J. J. Dibner, and M. Vázquez-Añón. 2006. Absorption of 2-hydroxy-4-methylthiobutyrate and conversion to methionine in lambs. J. Dairy Sci. 89:1072-1080. https://doi .org/10.3168/jds.S0022-0302(06)72175-0.

Michel, G., C. Claude, and G. Georges. 2001. Process for the preparation of 2-hydroxy-4-methylthiobutyric acid esters. US Pat. No. 6660880B2.

Michel, M., C. Claude, and G. Georges. 2000. Process for the preparation of alkyl 2-hydroxy-4-(methylthio)butyric acid esters by the sulfuric acid hydrolysis and esterification of 2-hydroxy-4-(methylthio)butyronitrile with alkanols. Patent No. WO2000059877.

Ordway, R. S., S. E. Boucher, N. L. Whitehouse, C. G. Schwab, and B. K. Sloan. 2009. Effects of providing two forms of supplemental methionine to periparturient Holstein dairy cows on feed intake and lactational performance. J. Dairy Sci. 92:5154-5166. https://doi.org/10.3168/jds.2009-2259.

Pisulewski, P. M., H. Rulquin, J. L. Peyraud, and R. Verité. 1996. Lactational and systemic response of dairy cows to postruminal infusions of increasing amounts of methionine. J. Dairy Sci. 79:1781-1791. https://doi.org/10 $.3168 /$ jds.S0022-0302(96)76546-3.
Robert, J. C., T. d'Alfonso, G. Etave, E. Depres, and B. Bouza. 2002. Quantifying the metabolizable methionine contribution of a liquid or powder presentation of 2-hydroxy-4(methylthio) butanoic acid isopropyl ester (HMBi). J. Dairy Sci. 85(Suppl. 1):71. (Abstr.)

Robert, J. C., C. Richard, and B. Bouza. 2001. Influence of monomer and dimer forms of isopropyl ester of HMB on the supply of metabolizable methionine to the blood of ruminants. J. Dairy Sci. 84(Suppl.1):281. (Abstr.)

Rulquin, H., B. Graulet, L. Delaby, and J. C. Robert. 2006. Effect of different forms of methionine on lactational performance of dairy cows. J. Dairy Sci. 89:4387-4394. https://doi.org/10.3168/jds.S0022-0302(06)72485-7.

Rulquin, H., and J. Kowalczyk. 2003. Development of a method for measuring lysine and methionine bioavailability in rumen-protected products for cattle. J. Anim. Feed Sci. 12:465-474. https://doi.org/10.22358/jafs/67723/ 2003.

Sadaba Zubiri, I., E. Taarning, and D. Tzoulaki. 2016. A process for the preparation of methionine alpha-hydroxy analogues from sugars and derivatives thereof. Pat. No. WO2016174231.

Schwab, C. G., and G. A. Broderick. 2017. A 100-year review: Protein and amino acid nutrition in dairy cows. J. Dairy Sci. 100:10094-10112. https:/ /doi.org/10.3168/jds.2017-13320.

Schwab, C. G., N. L. Whitehouse, A. M. McLaughlin, R. K. Kadariya, N. R. St-Pierre, B. K. Sloan, R. M. Gill, and J.-C. Robert. 2001. Use of milk protein concentration to estimate the methionine availability of two forms of 2-hydroxy-4-methylthio butanoic acid (HMB) for lactating cows. J. Dairy Sci. 84(Suppl. 1):35. (Abstr.)

Whitehouse, N. L., C. G. Schwab, and A. F. Brito. 2017. The plasma free amino acid dose-response technique: A proposed methodology for determining lysine relative bioavailability of rumen-protected lysine supplements. J. Dairy Sci. 100:9585-9601. https://doi.org/10.3168/jds.2017-12695.

\section{Notes}

A. Kihal $\odot$ https://orcid.org/0000-0003-2316-9573

M. Rodriguez-Prado ㄴ https://orcid.org/0000-0002-5106-7657

S. Calsamiglia $\odot$ https://orcid.org/0000-0002-0978-3799

This project was funded by Kemin Animal Nutrition and Health (Herentals, Belgium).

The authors declare that they have no conflicts of interest. 